\title{
VALIDATION OF ASH OPTICAL DEPTH AND LAYER HEIGHT FROM IASI USING EARLINET LIDAR DATA
}

\author{
D. Balis ${ }^{1}$, N.Siomos ${ }^{1}$, M. Koukouli ${ }^{1}$, L. Clarisse ${ }^{2}$, E. Carboni ${ }^{3}$, L.Ventress ${ }^{3}$, R. Grainger ${ }^{3}$, L. Mona ${ }^{4}$ \\ and G. Pappalardo ${ }^{4}$ \\ ${ }^{1}$ Aristotle University of Thessaloniki,Greece,*Email:balis@auth.gr \\ ${ }^{2}$ Université Libre de Bruxelles, Brussels, Belgium \\ ${ }^{3}$ University of Oxford, Atmospheric, Oceanic \& Planetary Physics Clarendon Laboratory, United \\ Kingdom \\ ${ }^{4}$ Consiglio Nazionale delle Ricerche, Istituto di Metodologie per l'Analisi Ambientale (CNR-IMAA), Tito \\ Scalo, Potenza, Italy
}

\begin{abstract}
The 2010 eruptions of the Icelandic volcano Eyjafjallajökull attracted the attention of the public and the scientific community to the vulnerability of the European airspace to volcanic eruptions. The European Space Agency project "Satellite Monitoring of Ash and Sulphur Dioxide for the mitigation of Aviation Hazards", called for the creation of an optimal End-to-End System for Volcanic Ash Plume Monitoring and Prediction. This system is based on improved and dedicated satellite-derived ash plume and sulphur dioxide level assessments, as well as an extensive validation, using among others ground-based measurements (Koukouli et al., 2014). The validation of volcanic ash levels and height extracted from IASI/MetopA is presented in this work with emphasis on the ash plume height and ash optical depth levels. European Aerosol Research Lidar Network [EARLINET] lidar measurements are compared to different satellite estimates for two eruptive episodes. The validation results are extremely promising within the estimated uncertainties of each of the comparative datasets.
\end{abstract}

\section{SATELLITE DATA}

Satellite data from IASI (Clerbaux et al, 2009) were provided by both the Universite Libre de Bruxelles, hereafter, ULB, and Oxford University, hereafter OXF. The algorithmic processing of the ULB institute (Clarisse et al., 2010; 2013) resulted in two different output types depending on the assumed volcanic ash characteristics whereas the algorithmic processing of OXF (Thomas et. al, 2009) resulted in four different output types, three of which assumed a fixed volcanic ash layer height analysis.

\section{VALIDATION DATA}

For the validation of the ash plume height as well as the optical depth of the ash plume, LIDAR data from the EARLINET network will were used [http://www.earlinet.org/]. EARLINET is the first aerosol lidar network on a continental scale with the main goal to provide data for the aerosol distribution over Europe at 25 participating stations. The available aerosol extinction and backscatter profiles make feasible the derivation of the ash plume height and optical thickness. A relational database, containing the output of the 4D analysis of EARLINET data related to the Eyjafjallajökull volcanic eruptions of 2010, has been set up and is freely available on request at http://www.earlinet.org (Pappalardo et al., 2013).

\section{RESULTS}

The values of each satellite product have been restricted within an area of variable radius, dependent of the satellite, around each EARLINET station. Out of those values the closest spatially and chronically to each station has been selected and has been compared with the respective EARLINET layer for each day. The spatial filtering has been applied before the temporal filtering. For all the satellite products a comparison of the Aerosol Optical Depth (AOD) has taken place. For the few satellite products that provided volcanic ash layer height information a comparison of volcanic ash layer height was also performed. The AOD of the EARLINET layers was derived by the layers' integrated backscatter 
coefficient multiplied by a constant conversion factor (lidar ratio) with a value of $50 \mathrm{sr}^{-1}$. An estimated $20 \%$ uncertainty on the EARLINET AOD was employed due to the uncertainty on the lidar ratio [typically between 40 and $60 \mathrm{sr}^{-1}$ ]. Concerning the layer height comparisons, the height of the center of the layers' mass was used and as estimated uncertainty, the distance between the mass center from the top and base of the later was employed. As far as the wavelength from which the AOD values were extracted is concerned; all the satellite AOD products were calculated using a wavelength of $550 \mathrm{~nm}$. Correspondingly, only the $532 \mathrm{~nm}$ AOD LIDAR measurements were used in the following comparisons.

The ash characteristics extracted by the IASI/MetopA instrument by the Oxford team have a double providence, since the team operates two different algorithms; one, henceforth called "nominal" applied to an optimal estimation technique which permits also the retrieval of ash plume height however is a lot more cost/time effective, and a second one, henceforth called "fast", is less time effective however requires a fixed plume height as input. As we can see in FIGURE 1, the ash AOD extracted from the IASI/MetopA Oxford nominal algorithm is quite low, with values rarely rising above the 0.2 level. Depending on the spatiotemporal choices imposed (only one is shown here), the number of common points for the entire European domain may rise from 18 to 36, with little effect on the accordance with the ground-based AOD assessment. This accordance provides quite promising correlation coefficients between 0.6 and 0.85 depending on the restrictions on the correlative dataset. Great care is needed though when interpreting these findings, due to the small amount of data points.

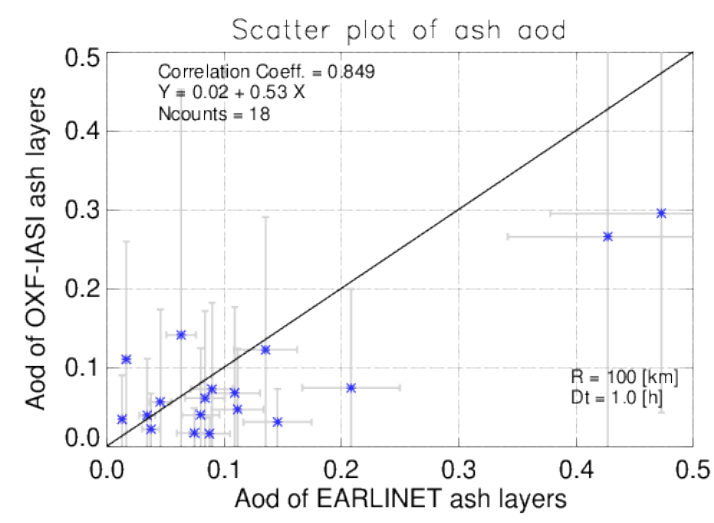

FIGURE 1. Scatter diagram between Oxford IASI nominal algorithm ash AOD and the co-located EARLINET stations for the Eyjafjallajökull eruptions in 2010 (coincidences within 100km and 1h).

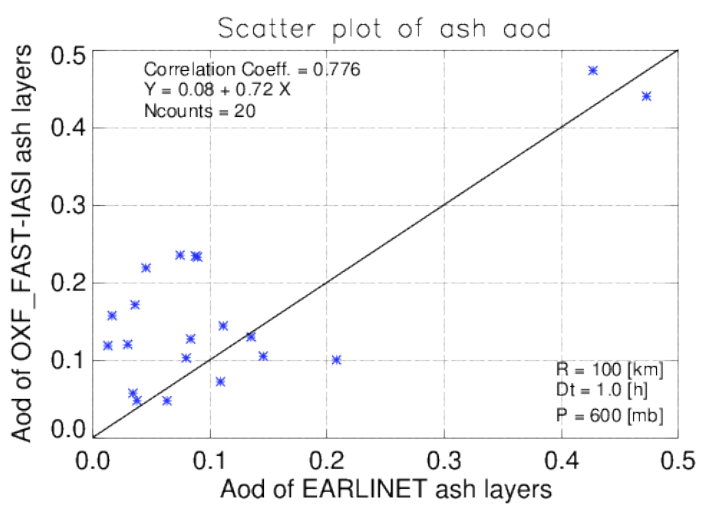

FIGURE 2 Scatter diagrams between the Oxford IASI fast algorithm ash AOD and the co-located EARLINET stations for the Eyjafjallajökull eruptions in 2010.

Concering the validation of the "fast" algorithm we present in FIGURE 2 the comparisons that show the best correlation with EARLINET data, which correspond to fixed ash layer height at $600 \mathrm{hPa}$.

Two different refractive indices were used as input to the direct fitting of the ULB IASI algorithm, resulting in two very similar ash AOD datasets. The comparisons when using the refractive index according to the Eyjafjallajökull ash [FIGURE 3] perform better with a correlation coefficient of 0.94 for the narrower spatiotemporal choice. Even though the sampling is poor, this product shows very promising results. 


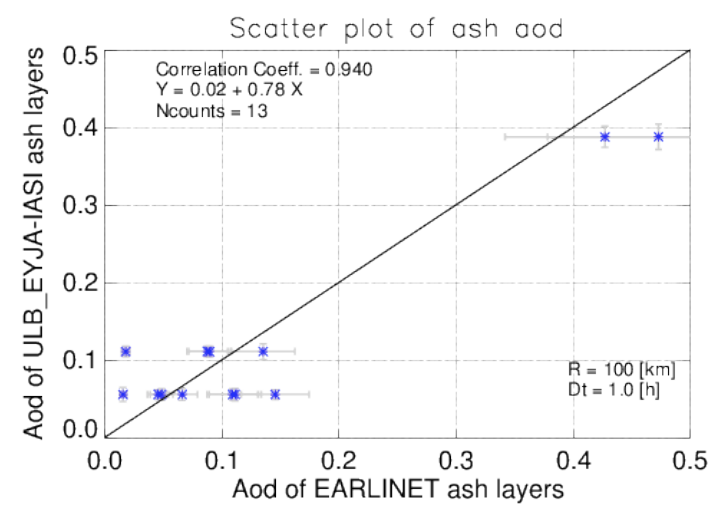

FIGURE 3. Scatter diagrams between the ULB IASI algorithm ash AOD and the co-located EARLINET stations for the Eyjafjallajökull eruptions in 2010 with assumed refractive indices according to Eyjafjallajökull ash.

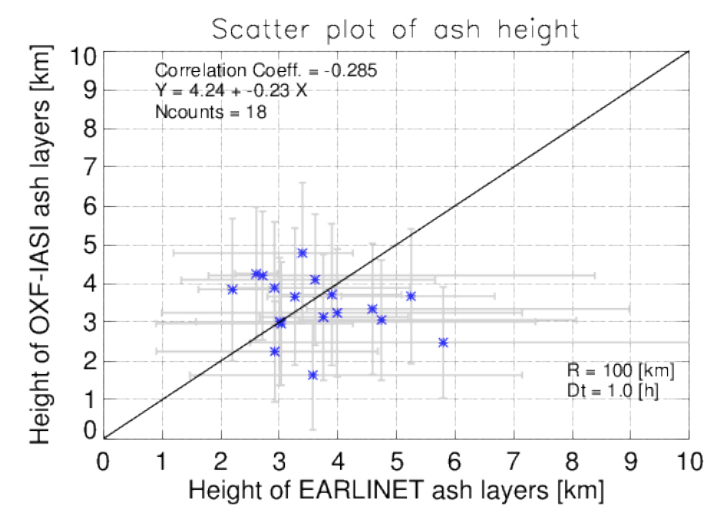

FIGURE 4. Scatter diagrams between the Oxford IASI nominal algorithm ash plume height and the co-located EARLINET stations for the Eyjafjallajökull eruptions in 2010.

In FIGURE 4 the comparison of the ash plume height extracted from the IASI/MetopA Oxford nominal algorithm and the one observed by the EARLINET network is shown. We note than the spread of plume heights found by the EARLINET network is higher than those found by the Oxford nominal IASI algorithm leading to rather poor comparisons. The scatter bars provide an indication of the amount of uncertainty inherent in both sets of observations.

\section{CONCLUSIONS}

In this paper we presented comparisons between volcanic ash AOD and ash layer height as these are estimated by IASI with ground based lidar measurements performed within EARLINET. Concerning the ash AOD the Oxford/IASI optimal estimation algorithm shows an acceptable correlation with the ground values, with coefficients ranging between 0.6 and 0.85 depending on the spatiotemporal co-location criteria used. Even though this comparisons provides a rather low amount of common values, these are of the same order of magnitude as the LIDAR ones. The Oxford/IASI Fast algorithm also provides AOD estimates with the same order of magnitude as the LIDAR, with correlations ranging between 0.7 and 0.8 for different algorithm setups. The ULB/IASI AOD estimates are also quite promising, with correlations ranging between 0.74 and 0.94 , depending on the assumed refractive index. All comparisons however suffer from the small number of co-locations found. As far as the ash plume height is concerned, the Oxford nominal IASI algorithm ash plume height comparisons are quite satisfactory with similar mean estimated ash layer height and spread.

\section{ACKNOWLEDGEMENT}

The authors would like to acknowledge the European Space Agency SACS-2/SMASH project. The ground-based EARLINET LIDAR database has been downloaded from www.earlinet.org. The financial support for EARLINET by the European Union under grant RICA 025991 in the Sixth Framework Program is gratefully acknowledged. Since 2011 EARLINET has been integrated in the ACTRIS Research Infrastructure Project supported by the European Union Seventh Framework Program

(FP7/2007-2013) under grant agreement no. 262254

\section{REFERENCES}

Clarisse, L., F. Prata, J.-L. Lacour, et al. (2010), A correlation method for volcanic ash detection using hyperspectral infrared measurements, Geophys. Res. Lett., 37, L19806, doi:10.1029/2010GL044828.

Clarisse, L., Coheur, P.-F., Prata, F., et al., (2013), A unified approach to infrared aerosol remote 
sensing and type specification, Atmos. Chem. Phys., 13, 2195-2221, doi:10.5194/acp-132195-2013.

Clerbaux, C., Boynard, A., Clarisse, L., et al., (2009), Monitoring of atmospheric composition using the thermal infrared IASI/MetOp sounder, Atmos. Chem. Phys., 9, 6041-6054, doi:10.5194/acp-9-6041-2009.

Koukouli, M. E., Balis, D. S., Dimopoulos, S., et al., SACS-2/SMASH validation report on the Eyjafjallajökull and Grimsvotn eruptions, http://sacs.aeronomie.be/ [last accessed, March 27 $\left.{ }^{\text {th }}, 2015\right], 2014$.

Pappalardo et al., Four-dimensional distribution of the 2010 Eyjafjallajokull volcanic cloud over Europe observed by EARLINET, Atmos. Chem. Phys., 13, 4429-4450, doi:10.5194/acp13-4429-2013

Thomas, G.E., E. Carboni, A.M. Sayer, et al., (2009), Oxford-RAL Aerosol and Cloud (ORAC): aerosol retrievals from satellite radiometers in Satellite Aerosol Remote Sensing Over Land (Eds: A.A. Kokhanovsky and G. de Leeuw), Springer. 